\title{
GUERRA E PROSTITUIÇÃO EM O CICLO DAS ÁGUAS, DE MOACYR SCLIAR
}

\section{WAR AND PROSTITUTION IN O CICLO DAS ÁGUAS, BY MOACYR SCLIAR}

Lunara Abadia Gonçalves Calixto*

Resumo: O livro O ciclo das águas, de Moacyr Scliar, publicado pela primeira vez em 1975, foi inspirado na questão do tráfico de mulheres judias trazidas para a América, entre o final do século XIX e meados do século XX, onde eram obrigadas a serem escravas sexuais na Zwi Migdal, uma rede internacional de prostituição. Essas mulheres ficaram conhecidas como polacas, termo que ficou pejorativamente associado a mulheres brancas estrangeiras e prostitutas. Conforme Moacyr Scliar (1985, p. 100): “O Ciclo das Águas tem como pano de fundo o 'tráfico de brancas' para a América Latina, particularmente para a Argentina e o Brasil, no período que vai de 1880 a 1930, aproximadamente". A narrativa entrecruza elementos históricos e ficcionais: a partir da protagonista Esther, há a abordagem do evento da trajetória vivida por centenas de imigrantes judias que se dirigiram para a América, onde acreditavam que encontrariam melhores condições de vida e maior liberdade, mas que, na verdade, acabavam entrando na prostituição para serem escravas sexuais. Quanto ao título da narrativa, $O$ ciclo das águas, há alusão às várias mudanças sofridas pela protagonista, no simbolismo próprio da água, que, em seus movimentos e ciclos, calmos e revoltos, límpidos e sujos, pode remeter a momentos da vida humana e, mais especificamente, à história dessas mulheres que foram prostituídas.

Palavras-Chave: Prostituição. O ciclo das águas. Polacas.

Abstract: The book $O$ ciclo das águas, by Moacyr Scliar, first published in 1975, was inspired by the issue of trafficking in Jewish women brought to America, between the late $19^{\text {th }}$ and mid- $20^{\text {th }}$ centuries, where they were forced to be sex slaves in the Zwi Migdal, an international network of prostitution. These women became known as polacas, a term that became pejoratively associated with foreign white women and prostitutes. According to Moacyr Scliar (1985, p. 100): “O ciclo das águas has as its background the 'white trade' to Latin America, particularly to Argentina and Brazil, in the period from 1880 to 1930, approximately". The narrative intertwines historical and fictional elements: from the protagonist Esther, there is an approach to the event of the trajectory experienced by hundreds of Jewish immigrants who went to America, where they believed they would find better living conditions and greater freedom, but who actually ended up entering prostitution to be sex slaves. As for the title of the narrative, $O$ ciclo das águas, there is an allusion to the various changes suffered by the protagonist, in

\footnotetext{
${ }^{*}$ Doutoranda em Estudos Literários pela Universidade Federal de Uberlândia (MG). E-mail: <lunaracalixto@gmail.com>.
} 
the symbolism of water itself, which in its calm and unruly, clean and dirty movements and cycles, can refer to moments of human life and, more specifically, to the story of these women who were prostituted.

Keywords: Prostitution. O ciclo das águas. Polacas.

Moacyr Scliar é um autor de grande renome na Literatura Brasileira, possuindo uma profícua obra que inclui diversos gêneros, tais como crônicas, contos, romances, textos de literatura infantil, bem como ensaios e artigos na área da medicina. Dentre a versatilidade de temas presentes em sua fortuna crítica, ressalta-se a abordagem da temática judaica em sua obra, que aparece não como religião, mas como uma circunstância cultural. Sendo de uma família de imigrantes judeus asquenazitas da Bessarábia, região sul da Rússia, Scliar procurou trazer para a sua escrita elementos da cultura judaica, bem como as adversidades sofridas pelo povo hebreu. Isso posto, o autor apresenta, por exemplo, o entrelugar ${ }^{l}$ do judeu imigrante, que se vê diante de duas culturas: a de origem e a do novo lugar onde está. Nesse sentido, por meio de alegorias e elementos fantásticos, viagens, travessias, migrações e metamorfoses, Scliar disserta sobre a situação do judeu no Brasil, que procura encontrar sua identidade: "a alegoria aponta para a natureza dilemática da realidade" (SZKLO, 1990, p. 25).

Desse modo, com o intuito de exibir um tema polêmico envolvendo a condição judaica, Moacyr Scliar publica, em 1975, O ciclo das águas. A obra abrange aspectos históricos e ficcionais sobre a trajetória vivida por centenas de imigrantes judias que, entre o final do século XIX até o momento da Segunda Guerra Mundial, foram levadas para a América, onde acreditavam que teriam melhores oportunidades, mas que acabaram sendo vítimas de uma rede internacional de prostituição. Essas mulheres ficaram conhecidas como polacas, termo genérico e pejorativo para designar as jovens que eram oriundas das regiões mais atrasadas economicamente da Europa Oriental. Na maioria das vezes, eram judias, pobres, sem instrução, o que as deixavam vulneráveis às abordagens de aliciadores. Essa circunstância é polêmica e, durante muito tempo, foi ocultada da tradição judaica:

A existência de prostitutas judias durante o período das imigrações para as Américas é um tema tabu para uma parte da comunidade judaica em todo o mundo. É um tema cercado pelo silêncio e pelo segredo. Uma narrativa

\footnotetext{
${ }^{1}$ Dentre as diversas definições para esse termo, cita-se Silviano Santiago (2000), que apresenta o entrelugar como um trânsito de culturas que interfere em uma tradição original, gerando uma nova identidade: "a dos mestiços, cuja principal característica é o fato de que a noção de unidade sofre reviravolta, é contaminada em favor de uma mistura complexa entre o elemento europeu e o elemento autóctone" (SANTIAGO, 2000, p. 15).
} 
"oficial” busca suprimi-las do processo histórico, colocando-as no território da amnésia (KUSHNIR, 1996, p. 47).

Contextualizando o momento histórico dessa narrativa, é preciso considerar que a prostituição de judias, que ficou conhecido como "tráfico de brancas", surge em razão dos pogroms $^{2}$ realizados no século XIX e meados do século XX, antecedendo a Segunda Guerra Mundial, os quais devastaram diversas regiões do Leste Europeu, ocasionando miséria. Embora a prostituição fosse uma prática condenada pela religião judaica ${ }^{3}$, muitos judeus adentraram nesse ramo, tanto pela perspectiva de um mercado rentável como também por ser uma forma de sobrevivência diante de um cenário de precariedade, conforme aponta Scliar (1985, p. 102): "em circunstâncias de miséria, de desagregação social, de luta desesperada pela sobrevivência, judeus recorrem aos mesmos métodos que outros usaram e usam".

Os pogroms também intensificaram a imigração de judeus para diversas partes do mundo, em busca de uma vida pacífica, longe da fome e da guerra. Conforme apresenta Kushnir (1996, p. 52):

A partir de meados do século XIX, as particulares condições vividas por toda a Europa justificaram um deslocamento ainda maior em busca de novas terras. Assim, se em 1880, cinco milhões de judeus viviam em territórios da Europa Oriental - parte oeste do Império Russo, Polônia, leste do Império AustroHúngaro que incluía a Galícia e România -, sessenta anos mais tarde, quatro milhões haviam fugido da pobreza, das ondas anti-semitas - os pogroms - e do serviço militar com destino às Américas, à Palestina, à África do Sul, à Austrália etc.

Isso posto, Moacyr Scliar cria um romance baseado nessas circunstâncias, em que a prostituição envolvendo judeus é uma das consequências das guerras e das perseguições a esse grupo. Em A condição judaica (1985), Scliar afirma que se inspirou em uma paciente polaca para escrever $O$ ciclo das águas, quando ele, recém-formado em medicina, a atendeu no Lar dos Velhos da Comunidade Israelita de Porto Alegre:

A personagem principal de $\mathrm{O}$ ciclo das águas foi inspirada na figura de uma velha prostituta judia, já falecida, a quem atendi como médico. O que mais me impressionava nesta mulher era a sua capacidade de sedução, em flagrante com sua deterioração física e mental (SCLIAR, 1985, p. 101).

\footnotetext{
${ }^{2}$ Palavra russa para se referir à perseguição violenta aos grupos judaicos.

${ }^{3}$ Em Deuteronômio, um dos livros que faz parte da Torá, está escrito: “17 Não haverá mulheres destinadas à prostituição sagrada entre as filhas de Israel nem homens destinados à prostituição sagrada entre os filhos de Israel. ${ }^{18}$ Não levarás para a casa do Senhor, teu Deus, por um voto qualquer, o salário de uma prostituta nem o salário de um prostituto; porque um e outro são abomináveis ao Senhor, teu Deus” (Dt 23, 17-18).
} 
A partir desse fato, $O$ ciclo das águas tem como protagonista Esther, uma moça judia pobre que vive em uma aldeia da Polônia, nos anos iniciais do século XX, que se torna vítima de uma rede internacional de prostituição. Ela passa por diversas circunstâncias ao longo do romance, sendo uma prostituta sedutora, depois uma caftina de grande poder, até que, na velhice, fica sozinha e demente. A história não segue uma linearidade, uma vez que passado e presente são descritos de forma entrecruzada, fazendo referência a distintas passagens em que a água está presente, em seu ciclo de transformações, para se relacionar com as mudanças na vida da personagem principal.

A jovem judia é filha de um mohel $^{4}$, que a mantém em um ambiente conservador, em que a tradição judaica é seguida rigorosamente. Assim, é criada dentro de um sistema patriarcal, de modo que deve demonstrar recato e submissão. O local onde habita é marcado pela pobreza, principalmente em razão dos pogroms. A vida de Esther começa a mudar quando reaparece Mêndele, um jovem judeu que havia ido para a América com a perspectiva de conquistar uma vida mais próspera: “É o menino que há dez anos foi para a América, e que nunca mais deu notícias. Agora volta homem, elegante num terno de casimira listrada. [...] Ela chega à estrada, detém-se. Ofegante, extasiada: como Mêndele está bonito" (SCLIAR, 2002, p. 12). Ao ver o rapaz de sua infância, Esther não se controla de alegria, ainda que tais reações efusivas fossem reprovadas pelo meio conservador onde vive: "Esperava (embora a mãe sempre lhe recomendasse recato) mais: um abraço, talvez um beijo" (SCLIAR, 2002, p. 12). Mêndele não demonstra o mesmo entusiasmo e se mantém apático e sério. Com efeito, retorna com o pretenso objetivo de conseguir uma esposa judia, a fim de que pudesse levá-la para a América, com a promessa de uma vida de riquezas: "Fala da vida da aldeia, pobre e monótona, e de sua vida na América: ganho, afirma, muito dinheiro; posso me casar contigo, posso te sustentar, posso te dar uma vida de rainha, na América. Rainha! Rainha na América! Rainha Esther! Ela ri. Irá com ele para onde ele quiser" (SCLIAR, 2002, p. 16).

A América foi um dos principais destinos de imigração dos judeus devido ao ideal de "novo mundo", propenso a riquezas e prosperidade. No entanto, nem todos conseguiam alcançar uma vida bem-sucedida onde aportavam. Assim, a partir de expectativas frustradas e do desespero provocado pelas guerras, a prostituição, no novo país, se constituía como uma alternativa de ganhos financeiros. Desse modo, com a perspectiva de grandes somas de dinheiro, muitos homens judeus entraram em redes internacionais de prostituição, sendo a Zwi

\footnotetext{
${ }^{4} \mathrm{O}$ mohel é o responsável pela realização dos preceitos religiosos no judaísmo; dentre eles, a circuncisão.
} 
Migdal a mais conhecida: "A Zwi Migdal tornou-se mundialmente conhecida e associada à existência de uma máfia judaica que dominava o tráfico de brancas em caráter mundial na rota Odessa/Buenos Aires” (KUSHNIR, 1996, p. 70). Na verdade, essa rede de prostituição funcionava sob a fachada de uma sociedade de ajuda mútua:

Fundada na Polônia, esta organização mantinha sua sede central em Buenos Aires, desde 1904, quando aparecera pública e legalmente como Sociedade Israelita de Socorros Mútuos Varsóvia. Responsável pela importação de muitas prostitutas para a Argentina e o Brasil, a sociedade atuava em várias cidades brasileiras, embora não de maneira tão imperiosa quanto naquele país, onde o desenvolvimento da prostituição garantia altas taxas de lucro. Vivendo radicalmente à margem da ordem instituída, os traficantes procuravam dar à sua associação um caráter legal à semelhança de outras existentes na comunidade israelita (RAGO, 2008, p. 323-324).

O personagem Mêndele é um dos aliciadores dessa rede internacional de prostituição, após o fracasso de sua tentativa de "fazer a América" no Brasil. Ela era um cáften ${ }^{5}$ e retorna à terra natal com a intenção de se casar com uma judia para colocá-la na rede de tráfico. No entanto, ele se apresenta à família de Esther como um homem de bem, que deseja uma esposa judia a fim de manter a tradição, e, assim, pede ao pai da jovem que autorizasse o casamento:

Sentados os dois, olhando a mesa. Mêndele levanta a cabeça e diz que quer casar com Esther. O mohel não responde logo. Aperta o copo de vinho nas mãos enrugadas, olha a mesa. Nas tábuas antes lisas surgiram sulcos, entalhes: sinais. A testa do homem se franze. Mêndele espera a resposta. Finalmente o mohel levanta os olhos. Sim, diz uma voz débil, quase imperceptível. Sim, repete, numa voz mais audível, vocês podem casar, têm a minha bênção. Sim! - quase gritando. Sim! (SCLIAR, 2002, p. 17).

A hesitação do mohel era justificável, pois sentia, a princípio, que algo não estava certo. Não obstante, por conhecer a família do rapaz, acaba concordando com o casamento, sem saber que a filha, nesse momento, estava sentenciada a ser uma prostituta. De fato, a ação de Mêndele, em propor casamento a uma jovem judia pobre, era comum entre os caftens:

Em geral, procuravam casar-se com as moças mais velhas, isto é, na faixa dos 20 anos e, aos poucos, iam trazendo as cunhadas para o mesmo tipo de vida. Várias vezes, as famílias em situação econômica extremamente precária vendiam as filhas, assinando falsos contratos com os caftens, embora muitas vezes também tudo ocorresse em completa ignorância, por desespero e esperança (RAGO, 2008, p. 325).

\footnotetext{
${ }^{5}$ O termo cáften, que se popularizou no Brasil como "cafetão", é uma "referência às tradicionais caftas - roupas usadas pelos judeus na Europa Oriental - unindo propositalmente ou não a imagem do judeu a essa atividade" (KUSHNIR, 1996, p. 68).
} 
As mulheres judias pobres da Europa Oriental eram consideradas as mais vulneráveis para o mercado do meretrício. Efetivamente, nas comunidades judaicas mais tradicionais dessa região, as mulheres não dispunham de autonomia e instrução formal, devendo se dedicar, principalmente, à vida doméstica. Com as ondas de pogroms promovendo crises econômicas, a desigualdade de gênero ficou ainda mais evidente, uma vez que elas não dispunham de meios para uma independência financeira e pessoal. Assim, tornaram-se alvos visados pelas redes de prostituição:

Nas pequenas aldeias, a educação era paga e religiosa, portanto destinada aos homens. O número de analfabetas era quase que total e mesmo sobre os ritos religiosos a maioria sabia apenas o básico. Sem preparo algum, sentiam que o novo mundo industrial jamais poderia alcançá-las (KUSHNIR, 1996, p. 65).

É assim que, com a chegada de Mêndele, Esther se entusiasma com a possibilidade de uma mudança positiva em sua vida. Com a aprovação do mohel, o casamento é celebrando segundo os preceitos judaicos, envolvendo toda a comunidade: "É uma festa bonita, mesmo. Toda a aldeia participa. A sinagoga está iluminada; no salão ao lado, a mesa do banquete" (SCLIAR, 2002, p. 17). Destaca-se que Mêndele contrata um fotógrafo para a cerimônia com o intuito de enviar uma foto de Esther para a rede de prostituição, sendo uma forma de avisar aos superiores a "conquista" obtida: "A última foto mostra-a sozinha, olhando para a câmara. Sorri. O homem que recebeu esta foto pelo correio também sorriu” (SCLIAR, 2002, p. 19).

Depois da festa, a jovem começa a perceber algumas atitudes inquietantes no noivo. Mêndele se mostra apático, sem direcionar a ela qualquer emoção, nem mesmo tocando-a: "Não a beijou. Nem sequer a tocou" (SCLIAR, 2002, p. 20). Sem uma noite de núpcias, os noivos vão para Paris, onde o cáften deveria instruí-la no mercado do sexo. Como as prostitutas francesas eram célebres, sendo consideradas modelos do meretrício de luxo, era ocorrente que os caftens levassem as vítimas do tráfico para a França, a fim de que elas aprendessem a agir como meretrizes francesas, para que depois fossem enviadas a outros países e, assim, fossem mais valorizadas financeiramente. Esther, até esse momento, não sabia da sua real situação.

Logo chegam a um hotel, que, na verdade, era um cabaré disfarçado. Lá ela vê casais em uma orgia, algo que a deixa surpresa. Todavia, acreditava que o esposo teria uma razão para conduzi-la a esse lugar, como consumar o casamento: 
Ela acabou concordando, sabendo que o mohel não gostaria daquilo, não gostaria nem um pouco, mas tendo a esperança que o cabaré talvez mudasse as coisas: dançariam de rosto colado e depois voltariam para o hotel e ele a beijaria na testa, na boca, no pescoço - primeiro suave, depois voraz. Vorazes, os dois. Apaixonados, como devem ser os jovens esposos (SCLIAR, 2002, p. 21).

Mêndele, no entanto, não tem relações sexuais com a esposa, mantendo-se sempre distante. Frustrada, Esther começa a explorar o lugar e vê uma estatueta de sereia de um abajur, que a fascina. Esse fato é importante porque a jovem estabelece uma conexão com essa figura, associando-a a si mesma:

Esther se aproxima, mira curiosa os detalhes do rosto delicadamente trabalhado. A boca, constata, se entreabre num sorriso discreto, um pouco tímido, um pouco triste; mas os globos oculares, representados como superfícies esféricas, lisas, vazias de qualquer expressão, dão à face um ar obsceno. Contraste ainda mais chocante: seios pequenos, delicados - e uma cauda escamosa, enrodilhada sobre o recife. Cauda de grande peixe (SCLIAR, 2002, p. 23).

Ressalta-se que a sereia, como um ser híbrido (metade humana e metade peixe), representa a condição dualista que Esther vive no romance: a filha judia de mohel, que deve viver a tradição, e a prostituta sedutora que se torna. Moacyr Scliar utiliza, em outros romances, uma figura híbrida para estabelecer um parâmetro com a condição do judeu imigrante. De fato, como afirma Berta Waldman (2003, p. 184):

Embora Moacyr Scliar tenha se cercado de informações históricas, elas são ficcionalizadas. No intervalo entre ficção e história, entre duas culturas, também Scliar, como sua personagem, se faz representar simbolicamente pela sereia, não só porque ela junta suas metades diversas, mas também porque, como escritor, ele une-se a ela em seu canto (WALDMAN, 2003, p. 184).

Após Esther tomar a estatueta da Pequena Sereia para si, Mêndele deixa a esposa sozinha com um homem desconhecido, que a força a ter relação sexual:

Abraça-a. Beija-lhe o pescoço. Vai-te! - empurra-o. Sorrindo sempre, ele começa a desabotoar-lhe o vestido. Ela, imóvel, olha-o. Vê Mêndele, parado perto da porta, os olhos esgazeados postos nela. Estende a mão - mas o homem já a arrasta para um sofá. Mêndele, murmura. O homem deita sobre ela. Já não vê mais Mêndele. [...] Mãe, é o que ela quer gritar. Mãe. Não grita: o homem beija-a com fúria. Vira o rosto. Mas de repente já não resiste: beija-o também. Sente a mão dele entre as coxas. Estremece... (SCLIAR, 2002, p. 23-24). 
Percebe-se que, apesar da resistência inicial, Esther acaba se rendendo. Na verdade, embora o sexo fosse algo tabu para as mulheres do meio onde vivia, a jovem tinha curiosidade sobre esse assunto e esperava que Mêndele, como seu esposo, lhe proporcionasse os prazeres que ansiava. Desse modo, esperando uma explicação sobre o que havia acontecido, e ainda com esperanças de que o marido consumasse o casamento, ela o procura, tentando seduzi-lo:

Levantou-se, foi até o espelho. Via uma mulher bonita, com um brilho ousado nos olhos. Isto era o que ela via, e ficou satisfeita. Voltou-se para Mêndele, sorrindo. De ânimo brincalhão, puxou-o para dançar. [...] Ela chegava-se a ele, beijava-o. Tentou seduzi-lo, ele resistiu. Ela esbofeteou-lhe, gritou, chorou; ele sempre em pé, imóvel, a cabeça baixa. Ela atirou-se à cama e adormeceu (SCLIAR, 2002, p. 25).

Não conseguindo realizar o seu intento, Esther adquire uma nova identidade. Após ter realizado o que podia para chamar a atenção de Mêndele, decide que não iria mais ser a jovem ingênua que confiava no marido. Passa a exalar sua sedução, ignorando o esposo. Logo seguem viagem de navio para a América do Sul, mas Mêndele adoece, morrendo de pneumonia. Esther não se abate com a morte e, no intuito de se vingar, mantém relações sexuais com o médico que o atendera:

Naquela noite não; mas na seguinte sim, dormiu com o médico, um russo simpático, de barba negra, um aristocrata que lhe sussurrava ao ouvido doces palavras em polonês, enquanto o grande navio cortava as ondas rumo à América. Ela mergulhava o rosto na grande, na cheirosa barba, doida de prazer, ah, meu Deus, eu não sabia que era tão bom! Turbilhão de prazer (SCLIAR, 2002, p. 30).

É a partir desse momento que Esther conhece os prazeres sexuais que ansiava, mas que eram proibidos para o seu gênero. Essa experiência sexual se constitui como um marco em sua vida, porque é quando ela se permite viver livremente a sua sexualidade, obtendo autoconfiança, algo influenciaria sua vida futura como prostituta.

Após o episódio com o médico, o navio chega à Argentina e, somente nesse momento, Esther descobre que se tornara uma escrava sexual, uma vez que aparece um novo cáften: Leiser, o chefe latino-americano da organização de escravas brancas. Ele lhe toma as malas e a leva para um bordel de Buenos Aires. Assim, ela percebe a gravidade de sua situação: "Sentiuse desamparada; teve vontade de rezar, mas não rezou. Não rezava mais. Não era digna. Se o pai, o santo mohel soubesse" (SCLIAR, 2002, p. 30). Esther não se considerava mais digna do pai porque a prostituição era vista como algo abominável para a religião israelita, e quem se 
envolvia com essa prática era julgado como impuro: há “o repúdio da comunidade judaica ao lenocínio, o que resultou em isolamento dos traficantes e das mulheres; eram considerados tmeyim (impuros) e enterrados fora dos muros e dos cemitérios” (SCLIAR, 1985, p. 100-101).

Sem outra opção, Esther é conduzida para o bordel chamado “Casa dos Prazeres”. Apesar de ter a liberdade privada, ela consegue se acostumar com o lugar, tornando-se a melhor prostituta. Ademais, permite-se viver os prazeres que o sexo poderia proporcionar. Ela adquire novos hábitos para se adequar ao papel de prostituta e se afeiçoa à nova vida: “Aprendendo artes do amor, e o tango; o tango, gostando muito do tango. Vestindo-se bem, preferindo muito o couro, o macio couro das reses argentinas. E peles. Tomando champanhe com fazendeiros do interior e com ricaços da capital” (SCLIAR, 2002, p. 33).

Logo o prostíbulo de Leiser, em Buenos Aires, é denunciado, e todos vão para o Brasil, em Porto Alegre. Nesse momento, nota-se que Esther passa a gostar da vida na prostituição, não percebendo a dominação exercida sobre ela, pois vivia em meio ao luxo, algo inédito em sua vida marcada pela pobreza na Polônia. Em pouco tempo, cede à pressão do cáften e muda a aparência para se parecer com uma meretriz francesa: "Pintava-se muito, também. Usava póde-arroz Coty, um batom bem escarlate, sombras negras ao redor dos olhos. O cabelo, antes castanho, estava oxigenado e frisado. Como em Buenos Aires, vestia-se bem, mas preferia agora a seda" (SCLIAR, 2002, p. 38).

A jovem judia se torna célebre no bordel porto-alegrense, sendo a mulher mais desejada: "Esther: bela, alegre, bem vestida, a mais querida do bordel" (SCLIAR, 2002, p. 39). As novidades que experimenta, os luxos que estão à sua disposição e os prazeres sexuais que vivencia fazem com que ela avalie sua vida de modo positivo: "É boa a vida, pensava, comendo bombons licorosos. Hum! Se fechavam de prazer: os olhos” (SCLIAR, 2002, p. 41). Na verdade, essas circunstâncias se constituem como uma forma de submissão, embora a jovem não percebesse. Ela vê como natural a condição em que está, não se atentando que ainda era uma escrava sexual. De fato, como apresenta Bourdieu (2018, p. 22):

Quando os dominados aplicam àquilo que os domina esquemas que são produto da dominação ou, em outros termos, quando seus pensamentos e suas percepções estão estruturados de conformidade com as estruturas mesmas da relação da dominação que lhes é imposta, seus atos de conhecimento são, inevitavelmente, atos de reconhecimento, de submissão.

Entretanto, com o passar do tempo, Esther começa a repensar sua condição judaica. Por ser filha de um mohel, não deixa de se sentir culpada por estar fazendo algo contra a religião: 
"Sonhando com o pai. O mohel de pé junto à cama dela - leito impuro - apontando-a com dedo acusador, declarando-a maldita" (SCLIAR, 2002, p. 34). De fato, ela percebe que é rechaçada por onde passa: "Com a comunidade judaica Esther não tem nenhum contato. Recusam-na" (SCLIAR, 2002, p. 43). Ademais, a falta de contato com a família começa a atormentá-la: "Nunca receberá uma carta de sua mãe. A mãe decerto está morta; encerrada num caixão de pinho, decompõe-se lenta sob a terra da Polônia, enquanto longe, em Porto Alegre, a filha sofre. Mãe, por que me deixaste? - grita - Por que fizeste isto com tua filha?” (SCLIAR, 2002, p. 43). Ela só consegue conciliar essa situação com o alter ego da Pequena Sereia:

O protagonista, na condição de eterno estrangeiro, isolado no meio dos outros e sempre com sua segurança ameaçada, se deixa levar para a fantasia, para o mundo do faz-de-conta. Sonhando com triunfos imaginários, ele se consola; seu mal-estar não parece tão profundo. Daí a impressão de dor e de alívio. Compensa-se através do devaneio (SZKLO, 1990, p. 61).

Vivendo momentos de solidão, Esther se envolve com um jovem cliente judeu chamado Rafael, por quem se apaixona. Ela engravida, mesmo sabendo que isso deixaria Leiser furioso. O caso, todavia, não dura, e quando o cáften descobre, tenta obrigá-la a fazer um aborto. A judia se nega e, após uma discussão violenta com o seu explorador, resolve fugir e abrir o próprio bordel com o dinheiro de um antigo cliente. Como havia sido uma prostituta de sucesso, ela acredita que conseguiria ser uma caftina melhor que Leiser.

A partir dessa circunstância, Esther começa uma nova fase em sua vida. Logo dá à luz um filho, o qual dá o nome Marcos. Ela tenta criá-lo dentro dos preceitos judaicos, a fim de compensar a vida fora da religião que levava: “a mãe queria que ele fizesse o bar-mitzvá; que lesse na sinagoga o seu trecho do Torá; que ingressasse, enfim, na comunidade dos homens judeus" (SCLIAR, 2002, p. 81). Percebe-se que, embora tenha desafiado os princípios do judaísmo, ela não consegue abandonar sua condição judaica e tenta redimir-se dos desvios que vivenciou, proporcionando ao filho uma criação dentro da tradição hebraica.

Esther inaugura seu bordel com o nome de Casa da Sereia, em referência à estátua de sereia que havia pegado no hotel em Paris, a qual carregava para toda parte. Desse modo, a Casa da Sereia se torna a "Casa da Esther", sendo um local seu, onde sua vida estava livre de caftens e de interdições da religião, que ainda a oprimiam. O símbolo da sereia, portanto, representa algo vital para sua identidade, pois permite que encontre o equilíbrio entre as suas identidades discrepantes: 
No romance, a sereia metaforiza a ambivalência cultural de Esther presa ao judaísmo tradicional e à sua vivência no âmbito de uma cultura de maioria cristã, a sua condição ambígua de emigrante e imigrante, de prostituta e mãe, mas, principalmente, sua natureza feminina, espécie de arquivo que guarda o segredo daquilo que os homens desejam nas mulheres, e que não podem alcançar para continuar desejando-as (WALDMAN, 2003, p. 182).

Sempre agarrada à Pequena Sereia, Esther obtém sucesso em seu prostíbulo. Procurando deixar o seu passado de polaca para trás, muda o seu sobrenome judeu, Markowitz, para ser a madame francesa Esther Marc:

Sou francesa, dizia aos clientes mais curiosos. Esther Marc era agora o seu nome, não mais Esther Markowitz. Um advogado lhe providenciara novos papéis. Vestia-se bem: longos vestidos escuros, jóias. Um cabeleireiro vinha penteá-la todos os dias. Entre seus clientes estavam figuras de projeção: o deputado Deoclécio, filho do fazendeiro Mathias, vinha todas as sextas-feiras. Visitantes de outros Estados eram encaminhados à Casa (SCLIAR, 2002, p. 92).

Deixando o papel de prostituta para trás, Esther se torna uma caftina de poder. Observase que, quando tem condições de ascender socialmente, ela não procura extinguir a prática da prostituição, mas sim trocar de papel com seu opositor para estar em uma posição de comando. Todavia, o sucesso de Esther não é duradouro, uma vez que tem o bordel denunciado e desapropriado pela prefeitura. Após anos de luxo e prazeres, chega a um período de decadência. Começa a sofrer de demência, até que é internada em um asilo. Mesmo idosa e sem reconhecer ninguém, ainda mantém sua sensualidade ativa, tentando seduzir os homens que apareciam: “Que homem bonito! Senta aqui, querido. Vamos conversar. Como é o teu nome?" (SCLIAR, 2002, p. 155).

A partir da história de Esther, depreende-se que é uma personagem judia que foi obrigada a se prostituir, mas que encontrou na prostituição tanto a glória (conhecendo o prazer interdito e obtendo ganhos financeiros) como também o declínio (a solidão e a demência). Todavia, não percebe com nitidez a objetificação vivida. Assim, ainda que tenha desafiado o patriarcalismo, não consegue se sobrepor a ele 


\section{Considerações Finais}

Moacyr Scliar, em $O$ ciclo das águas, apresenta, de forma ficcionalizada, o passado de mulheres judias que, como a protagonista Esther, vivenciaram a prostituição e a privação de sua liberdade. É importante ponderar que a guerra e as perseguições realizadas em comunidades judaicas do Leste Europeu, entre os séculos XIX e XX, contribuíram para que a prostituição tenha sido um destino imposto a várias dessas mulheres em situação de vulnerabilidade. Sendo relegadas à condição de mercadoria de tráfico sexual, viveram à mercê de caftens, perdendo a liberdade e o acesso à própria sexualidade. Embora o tema seja tabu, Scliar não se intimida de expor essa circunstância que fez parte do passado judaico. O tráfico de mulheres judias para o meretrício é algo desconhecido por muitos, e o autor traz à tona esse assunto.

Por fim, ao criar a personagem Esther, Moacyr Scliar demonstra, de forma irônica, como uma personagem criada em um ambiente patriarcalista e religioso pode ser levada a se prostituir por outros de sua cultura. No entanto, a jovem judia encontra meios para desenvolver uma autonomia e inventar o próprio destino. Por meio da criação do alter ego da Pequena Sereia, consegue lidar com a situação ambivalente em que vive: a filha judia e a prostituta que sente prazer. No bordel, apesar de perder a liberdade como prostituta, também encontra poder quando se torna uma caftina. Ainda que perca tudo na velhice, inclusive a própria consciência, não perde a sedução que a tornou uma mulher empoderada e desafiadora. Assim, Esther representa uma mulher que contesta o destino imposto a ela no processo de prostituição que viveu, negando-se a perder a essência de sua sexualidade que a tornara única.

\section{Referências}

BÍBLIA. Nova Bíblia Pastoral. São Paulo: Paulus, 2014.

BOURDIEU, Pierre. A dominação masculina. Tradução de Maria Helena Kühner. 6. ed. Rio de Janeiro: BestBolso, 2018.

KUSHNIR, Beatriz. Baile de máscaras: mulheres judias e prostituição: as Polacas e suas Associações de Ajuda Mútua. Rio de Janeiro: Imago Ed, 1996. 
RAGO, Margareth. Os prazeres da noite: prostituição e códigos da sexualidade feminina em São Paulo, 1890-1930. 2. ed. São Paulo: Paz e Terra, 2008.

SANTIAGO, Silviano. Uma literatura nos trópicos. 2. ed. Rio de Janeiro: Rocco, 2000.

SCLIAR, Moacyr. A condição judaica. Porto Alegre: L\&PM, 1985.

O ciclo das águas. Porto Alegre: L\&PM, 2002.

SZKLO, Gilda Salem. O bom fim do shtetl: Moacyr Scliar. São Paulo: Perspectiva, 1990.

WALDMAN, Bertha. Entre braços e pernas: prostitutas estrangeiras na Literatura Brasileira do Século XX. In: - Entre passos e rastros: presença judaica na literatura brasileira contemporânea. São Paulo: Perspectivas: FAPESP: Associação Universitária de Cultura Judaica, 2003, p. 169-189. 